Intecoms: Journal of Information Technology and Computer Science

Volume 2 Nomor 1, Juni 2019

e-ISSN : 2614-1574

p-ISSN : 2621-3249

DOI : https://doi.org/10.31539/intecoms.v2i1.738

\title{
PENDETEKSI KESAMAAN DOKUMEN PADA SISTEM INFORMASI PENDAFTARAN PROPOSAL SKRIPSI DENGAN PENDEKATAN ALGORITMA RABIN-KARP
}

\section{DOCUMENT EQUALITY DETECTION IN INFORMATION SYSTEM OF THESIS PROPOSAL REGISTRATION WITH RABIN-CARP ALGORITHM APPROACH}

\author{
Pandu Pratama Putra ${ }^{1}$, Afriansyah ${ }^{2}$, Muhammad Syaifullah ${ }^{3}$ \\ STMIK AMIK Riau ${ }^{1,3}$ \\ Universitas Lancang Kuning ${ }^{2}$ \\ pandupratamaputra91@gmail.com ${ }^{1}$
}

\begin{abstract}
Plagiarism is a significant problem in many areas, including universities. plagiarism is usually performed on digital content is to copy-paste of the original document. To anticipate, we need a way to analyze the technique of plagiarism. There are several approaches that can be taken, for example by using a search algorithm Rabin-Karp string because these algorithms can be used to detect plagiarism in a text document. In the testing phase, the test documents used were three documents with similarity level categories of low, medium and high. From some of the testing that has been done, this approach can find the longest quote the same between the two text documents and measure the similarity of text documents. With this system will help prevent acts of plagiarism in the thesis proposal registration so that the absence of the same thesis.
\end{abstract}

Keywords: Plagiarism, Rabin-Karp algorithm, Similarity, Document

\section{ABSTRAK}

Plagiarisme adalah sebuah masalah yang cukup signifikan pada banyak bidang termasuk universitas. plagiarisme yang biasanya dilakukan terhadap konten digital adalah melakukan copy-paste terhadap dokumen asli. Untuk mengantisipasinya, dibutuhkan suatu cara yang dapat menganalisis teknik plagiarisme. Ada beberapa pendekatan yang bisa diambil, contohnya dengan mempergunakan algoritma pencarian string Rabin-Karp karena algoritma ini dapat digunakan untuk mendeteksi plagiarisme pada sebuah dokumen teks. Pada tahap pengujian, dokumen uji yang digunakan berjumlah tiga dokumen dengan kategori tingkat kemiripan rendah, sedang dan tinggi. Dari beberapa pengujian yang telah dilakukan, pendekatan ini dapat menemukan kutipan terpanjang yang sama di antara dua dokumen teks serta mengukur kemiripan dokumen teks. Dengan sistem ini akan membantu mencegah aksi plagiarisme pada pendaftaran proposal skripsi sehingga tidak adanya skripsi yang sama.

Kata Kunci: Plagiarisme, algoritma Rabin-Karp, Kesamaan, Dokumen

\section{PENDAHULUAN}

Plagiarisme menurut Kamus

Besar Bahasa Indonesia (KBBI) berarti menggambar atau menulis garis-garis gambaran atau tulisan yang telah tersedia (dengan menempelkan kertas kosong pada gambar atau tulisan yang akan ditiru), mencontoh atau meniru tulisan atau pekerjaan orang lain, mencuri karangan orang lain dan mengakui sebagai karangan sendiri, mengutip karangan orang lain tanpa seizin penulisnya (KBBI, 1997).

Kemampuan dosen di dalam melakukan kontrol dan penyeleksian masih terkendala dengan suatu database yang harus dicek dan diketahui dan dengan kemampuan daya ingat dari masing-masing dosen atau pembimbing, yang mungkin terbatas, sehingga terkadang satu dua judul terkadang lolos dan luput dari pantauan sehingga terjadi 
kemiripan atau bisa disebut plagiat karena sebagian isinya hampir sama, terkadang hanya dibedakan sedikit pada judulnya saja. Pendaftaran proposal skripsi pada masing-masing institusi pendidikan harusnya dilakukan secara cermat dengan melakukan program aplikasi yang mudah untuk dioperasikan sehingga pada saat yang tepat dan cepat dapat diketahui bahwa judul tersebut sudah ada yang mirip sampai berapa persen dari masing-masing proposal skripsi yang dilakukan pengujian. Melalui pengolahan data dokumen proposal skripsi ini maka bagaimana suatu proses pendaftaran proposal skripsi yang akan diajukan ada di dalam proposal skripsi yang sudah terdokumentasi secara database dapat diketemukan, Pencarian dokumen proposal skripsi yang mirip dapat diketahui secara cepat.

Pembandingan

kesamaan

dokumen pada dokumen proposal skripsi ini dilakukan dengan membandingkan dokumen teks dengan seluruh dokumen teks yang tersimpan di basis data. Hasil pembandingan dengan aplikasi deteksi kesamaan dokumen ini tidak menunjukkan bahwa mutlak telah atau tidak terjadi plagiarisme antara dokumen teks yang dibandingkan. Hasil tersebut hanya memberikan informasi berupa persentase kesamaan antara dokumen teks, karena hingga saat ini belum ada definisi universal tentang persentase dalam pengambilan tulisan milik orang lain.

Aksi plagiat dalam karya tulis sangatlah mungkin terjadi, untuk itu perlu dilakukan upaya-upaya sebagai pencegahan maupun pendeteksian, sehingga dalam tulisan ini akan dibahas mengenai pendeteksian plagiarisme dari sebuah dokumen dengan membandingkannya dengan sebuah dokumen lainnya.
Plagiarisme adalah penjiplakan atau pengambilan karangan, pendapat, dan sebagainya dari orang lain dan menjadikannya seolah karangan dan pendapat sendiri(KBBI, 1997). Menurut peraturan Menteri Pendidikan Nasional RI No. 17 Tahun 2010 tentang pencegahan dan penanggulangan plagiat di perguruan tinggi. Bab 1 pasal 1 ayat 1, plagiat adalah perbuatan secara sengaja atau tidak sengaja dalam memperoleh atau mencoba memperoleh kredit atau nilai untuk suatu karya ilmiah, dengan mengutip sebagian atau seluruh karya dan/atau karya ilmiah pihak lain yang diakui sebagai karya ilmiahnya, tanpa menyatakan sumber secara tepat dan memadai (PMPN RI, 2010).

Yang digolongkan plagiarisme yaitu menggunakan tulisan orang lain secara mentah, tanpa memberikan tanda jelas (misalnya dengan menggunakan tanda kutip atau blok alinea yang berbeda) bahwa teks tersebut diambil persis dari tulisan lain mengambil gagasan orang lain tanpa memberikan anotasi yang cukup tentang sumbernya (Utorodewo, 2007).

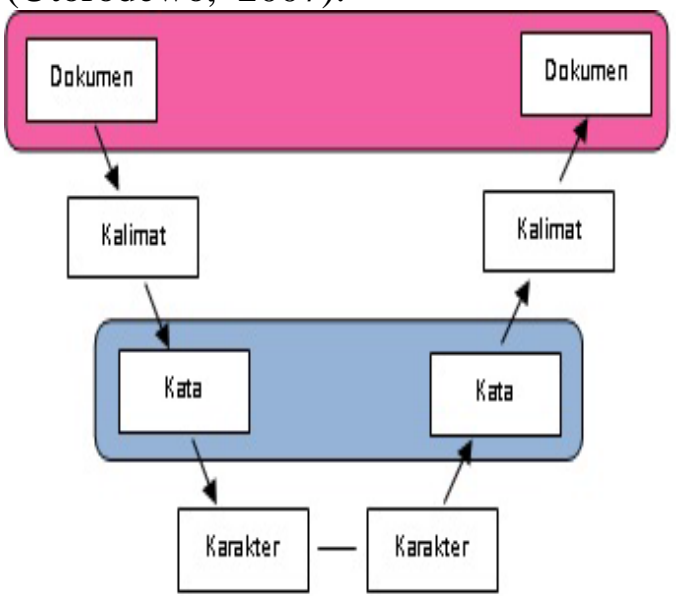

Gambar. 1 Hirarki Pengukuran Kesamaan Dokumen

Permasalahan yang terjadi pada pengukuran kemiripan karakter atau huruf adalah hanya dapat mengukur karakter atau huruf yang sama persis. Huruf a dan huruf A dianggap tidak 
sama. Pengukuran seperti ini banyak digunakan untuk mengukur keamanan password, memeriksa kata (spell checker) (Kurniawati et al. 2012).

Permasalahan yang terjadi pada pengukuran kemiripan kata adalah hanya dapat mengukur kata yang sama persis. Fenomena yang sering kali terjadi adalah masyarakat mengambil tulisan orang lain dan kemudian mengganti kata dengan sinonim katanya. Bentuk seperti ini tidak dapat diukur kemiripan dokumen apabila menggunakan pengukuran kemiripan kata karena tidak mempertimbangkan sinonim kata tersebut (Kurniawati et al. 2012).

\section{Permasalahan}

pengukuran

kemiripan yang juga terjadi adalah mengambil penulisan orang lain dengan cara hanya mengganti subjek kalimat atau hanya mengganti predikat atau objek ataupun keterangan. Solusi yang harus dipertimbangkan untuk permasalahan di atas adalah menentukan struktur kalimat (Kurniawati et al, 2012).

Permasalahan lain yang sering terjadi,selain mengganti kata dengan sinonim kata tersebut adalah posisi kalimat. Masyarakat yang mengambil penulisan orang lain, sering melakukan perubahan pada posisi kalimat. Contoh pada penulisan orang lain, kalimat yang diambil terletak pada kalimat pertama. Kemudian kalimat tersebut diletakkan pada kalimat kelima. Karena posisi berbeda maka tidak dapat diukur kemiripannya. Solusi yang harus dipertimbangkan adalah pengukuran semua kalimat pada dokumen satu terhadap semua kalimat pada dokumen kedua (Kurniawati et al, 2012).

Dalam ilmu sistem temu kembali informasi khususnya pada algoritma pendeteksi plagiarisme dokumen teks ada beberapa istilah yang tedapat dalam hal pemrosesan dokumen, diantaranya
(Rafles, 2013):

Preprocessing atau pembersihan teks merupakan tahapan yang dilakukan untuk mengubah data mentah menjadi data berkualitas yaitu data yang telah memenuhi persyaratan untuk diekseskusi pada sebuah algoritma. Bentuk pembersihan teks ini, dapat berupa menghilangkan spasi, tanda baca, simbol simbol, mengubah huruf kapital menjadi huruf kecil dan menghilangkan karakter-karakter yang tidak relevan lainnya.

Tokenizing merupakan tahap pemotongan kalimat menjadi kata pada sistem temu kembali informasi. Pemotongan kata ini dapat berbentuk satu kata (unigram atau uniword), dua kata (bigram atau biword), tiga kata (trigram atau triword), empat kata (quadgram atau quadword) dan seterusnya.

Irisan (intersection) merupakan tahapan untuk menemukan kata bertalian yang sama di antara dua dokumen teks.

Algoritma Rabin Karp adalah algoritma pencarian kata yang mencari sebuah pola berupa substring dalam sebuah teks menggunakan hashing. Algoritma ini sangat efektif untuk pencocokan kata dengan pola banyak. Salah satu aplikasi praktis dari algoritma Rabin Karp adalah dalam pendeteksian plagiarisme. Dalam ilmu komputer, algoritma Rabin-Karp adalah algoritma pencarian string yang dibuat oleh Michael O. Rabin dan Richard M. Karp pada tahun 1987 yang menggunakan hashing untuk menemukan salah satu dari satu set string pola dalam teks (Salmuasih \& Sunyoto, 2013).

PHP dikembangkan oleh Rasmus Lerdorf pada tahun 1994 yang pada awalnya mengembangkan sebuah perkakas yang digunakan sebagai engine parsing sebagai penterjemah 
beberapa macro. PHP (Hypertext Preprocessor) adalah bahasa pemrograman yang berjalan dalam sebuah wenserver dan berfungsi sebagai pengolah data pada sebuah server. Dengan menggunakan program PHP, sebuah website akan lebih interaktif dan dinamis (Andi, 2011).

SQL (Structure Query Language) adalah suatu bahasa komputer yang mengikuti standar American National Standard Institute (ANSI), yaitu sebuah bahasa standar yang digunakan untuk mengakses dan melakukan manipulasi sistem database (Muslih \& Purnama, 2013).

Xampp adalah perangkat lunak bebas, yang mendukung banyak sistem operasi, merupakan kompilasi beberapa program. Berfungsi sebagai server yang berdiri sendiri (localhost), yang terdiri atas program Apache, MySQL database, dan penerjemah bahasa yang ditulis dengan bahasa pemrograman PHP (Agustina, 2015)

\section{METODE PENELITIAN}

Metode yang penulis gunakan adalah metode waterfall. Secara garis besar metode waterfall mempunyai langkah-langkah sebagai berikut :

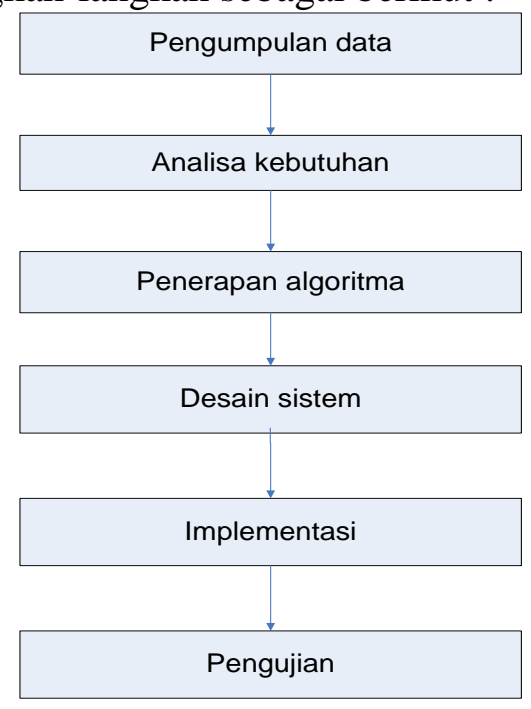

Gambar. 2 Waterfall Model
HASIL DAN PEMBAHASAN Analisa Kebutuhan

\section{Hardware}

Tabel 1. Spesifikasi Hardware

\begin{tabular}{lll}
\hline No & Hardware & \multicolumn{1}{c}{ Spesifikasi } \\
\hline 1 & Prosesor & Intel core i3 \\
2 & Memory & $2 \mathrm{gb}$ \\
\hline
\end{tabular}

\section{Software}

Tabel 2. Spesifikasi Software

\begin{tabular}{lll}
\hline No & Software & Spesifikasi \\
\hline 1 & Sistem operasi & Windows 7.0 \\
2 & Database & MySQ1 \\
3 & Web Server & Xampp \\
4 & Aplikasi Editor & Sublime \\
5 & $\begin{array}{l}\text { Bahasa } \\
\text { pemograman }\end{array}$ & PHP \\
\hline
\end{tabular}

\section{Penerapan Algoritma Rabin-Karp}

Diagram alir penerapan algoritma rabin karp dapat dijelaskan seperti Gambar berikut:

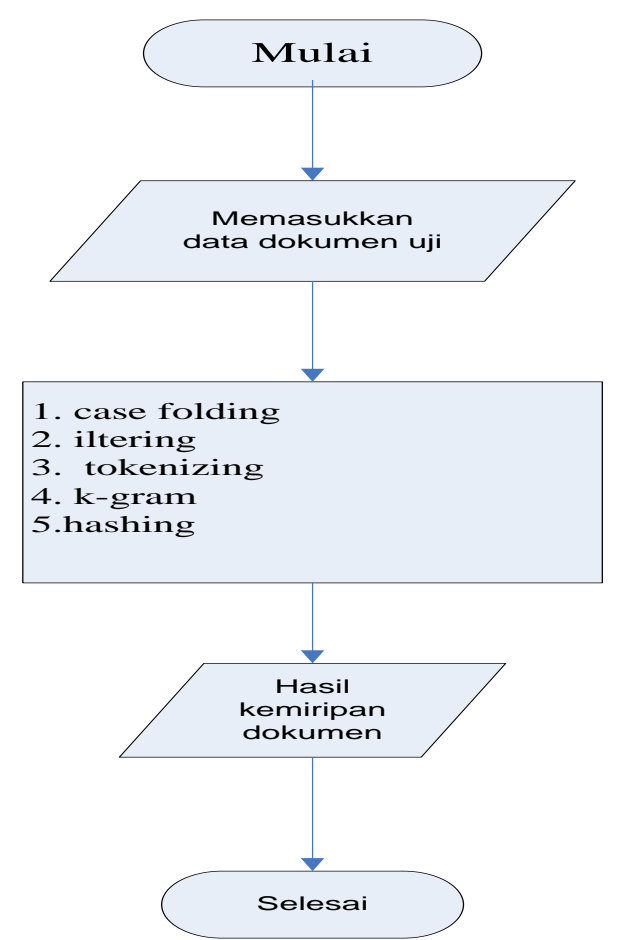

Gambar. 3 Diagram Alir 


\section{Perhitungan Manual}

Langkah - langkah penyelesaian :

1. Case folding

Mengubah semua huruf dalam dokumen menjadi huruf kecil, hanya huruf "a" sampai dengan huruf " $z$ " yang diterima kemudian menggabungkannya.

2. Filtering penting.

Membuang kata yang tidak Algoritma adalah kumpulan perintah Contoh : kata adalah dibuang Jadi: algoritma kumpulan perintah

3. Tokenizing $\mathrm{k}$ gram dengan basis 5

Memecahkan kata menjadi potongan - potongan dimana setiap potongan mengandung karater sebanyak $\mathrm{k}$ gram yang ditentukan

Contoh : algor lgori gorit oritm ritma itma \{\} tma \{\}$k$ ma \{\} ku a \{\} kum \{\} kump kumpu umpul mpula pulan ulan\{\} lan\{\}p an\{\}pe n\{\}per \{\}peri perin erint rinta intah

4. Nilai k gram kenilai hashing

Cara perhitungan hash menggunakan basis 9 :

Contoh :

Hashing=algor

$\left(a^{* 9^{\wedge}}\right)+\left(1^{*} 9^{\wedge}\right)+\left(g^{*} 9^{\wedge}\right)+\left(0^{*} 9^{\wedge}\right)+$ $\left(\mathrm{r}^{*} \mathbf{9}^{\wedge} \mathbf{0}\right)$

$=\left(97 * 9^{\wedge}\right)+\left(108 * 9^{\wedge}\right)+\left(103 * 9^{\wedge}\right)+($

$\left.111^{*} 9^{\wedge} \mathbf{1}\right)+\left(114^{*} 9^{\wedge} \mathbf{0}\right)$

$\mathbf{= 7 2 4 6 0 5}$

Hashing=lgori

$=$

$\left(1^{*} 9^{\wedge} 4\right)+\left(g^{* 9^{\wedge}}\right)+\left(0^{* 9^{\wedge}}\right)+\left(\mathrm{r}^{* 9^{\wedge}}\right)+$ $\left(i^{*} 9^{\wedge} \mathbf{0}\right)$

$=\left(108 * 9^{\wedge} 4\right)+\left(103 * 9^{\wedge} 3\right)+\left(111 * 9^{\wedge}\right)$

$+\left(114 * 9^{\wedge} \mathbf{1}\right)+\left(105 * 9^{\wedge} \mathbf{0}\right)$

$=793797$

Hashing=gorit
$=$

$\left(\mathrm{g}^{* 9^{\wedge}}\right)+\left(\mathrm{o}^{* 9^{\wedge}}\right)+\left(\mathrm{r}^{* 9^{\wedge}}\right)+\left(\mathrm{i}^{*} \mathbf{9}^{\wedge}\right)+$ $\left(\mathrm{t}^{*} \mathbf{9}^{\wedge} \mathbf{0}\right)$

$=\left(103 * 9^{\wedge} 4\right)+\left(111 * 9^{\wedge}\right)+\left(114 * 9^{\wedge}\right)$

$+\left(105 * 9^{\wedge} \mathbf{1}\right)+\left(116^{*} 9^{\wedge} \mathbf{0}\right)$

$=766997$

Dst.....

5. Menghitung nilai kemiripan (similarity)

Menghitung kemiripan dengan menggunakan rumus Dice's similarity coeeficient.

$\mathrm{S}=2 * \mathrm{C} /(\mathrm{A}+\mathrm{B}) * 100$

Dimana :

$\mathrm{S}=$ nilai similarity

$\mathrm{C}=$ jumlah $\mathrm{k}$ gram dengan nilai yang sama dari hasil banding dokumen

$\mathrm{A}$ dan $\mathrm{B}=$ jumlah dari kumpulan $\mathrm{k}$ grams dalam dokumen input dan banding

Hashing yang sama antar dokumen akan kita beri nama fingerprinting, adapun nilai hashing yang sama sebanyak 8 hashing yaitu:

$\begin{array}{llll}724605 & 793797 & 766997 & 821035\end{array}$

834973783203799177756349

$\mathrm{S}=2 * 8 /(22+19) * 100$

$=16 / 41 * 100$

$=39,02439 \%$ similarity

\section{Desain Sistem}

Gambaran umum sistem

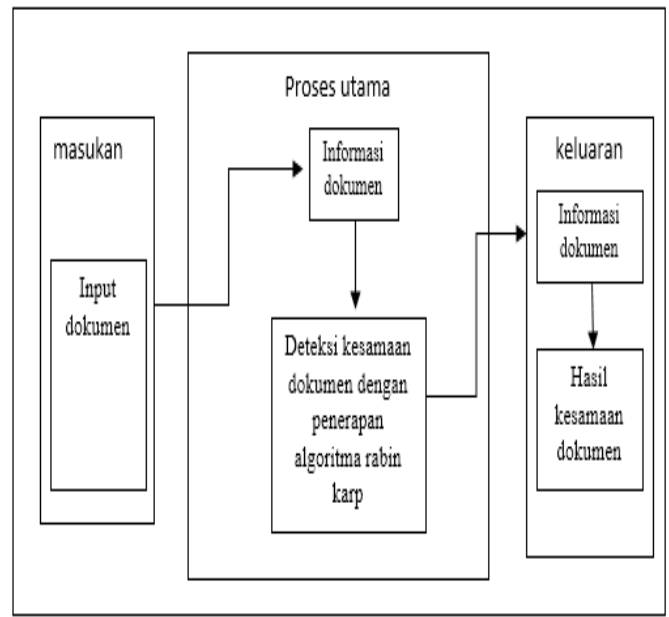

Gambar. 4 Gambaran Sistem 


\section{Implementasi sistem}

Dalam hal ini, implementasi dan pengujian sistem merupakan tahap dimana sistem siap dioperaskan pada keadaan yang sebenarnya, sehingga diketahui apakah sistem yang sudah diperbaharui dapat menghasilkan tujuan yang diinginkan. Berikut adalah desain dari penerapan pada tahap implementasi yang terdiri dari halaman - halaman aplikasi sistem sebagai berikut:

Tampilan Menu Login

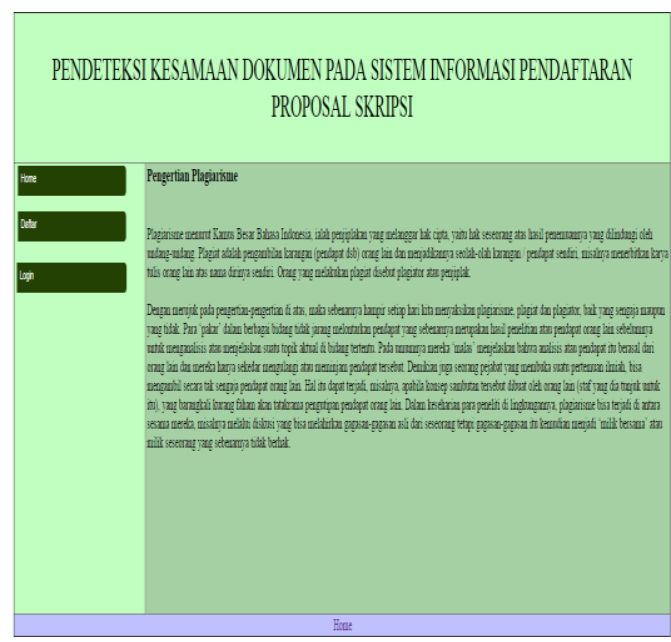

Gambar. 5 Menu Login

Tampilan menu beranda mahasiswa

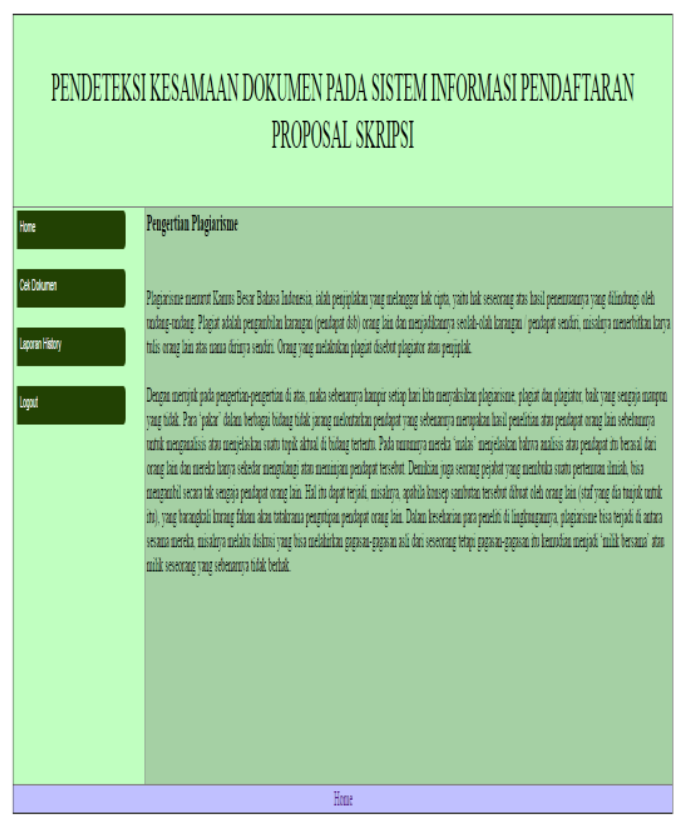

Gambar. 6 Menu Beranda Mahasiswa
Tampilan Menu Cek dokumen Mahasiswa

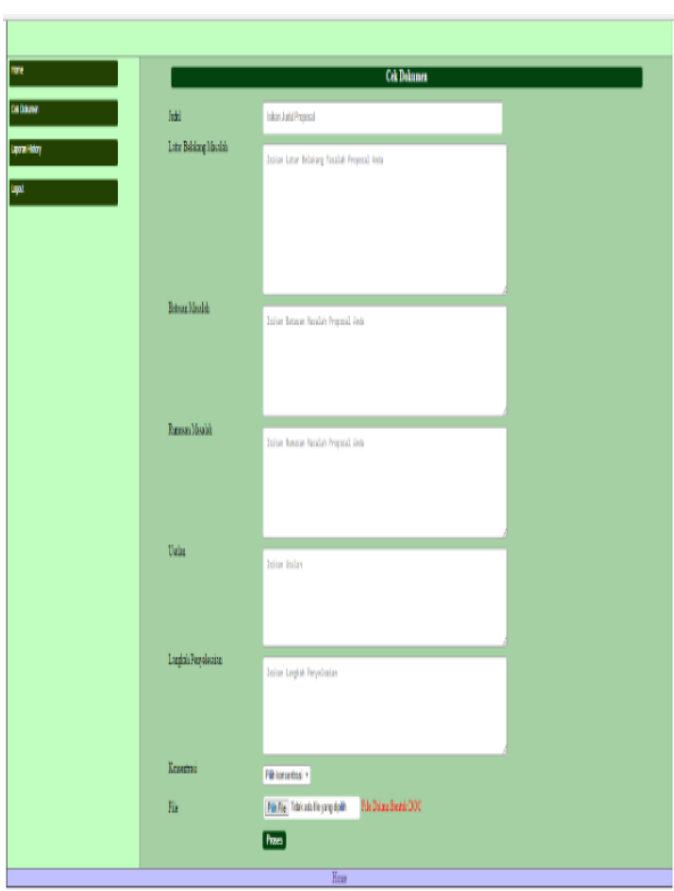

Gambar. 7 Menu Cek Dokumen

Tampilan Menu Laporan History Mahasiswa

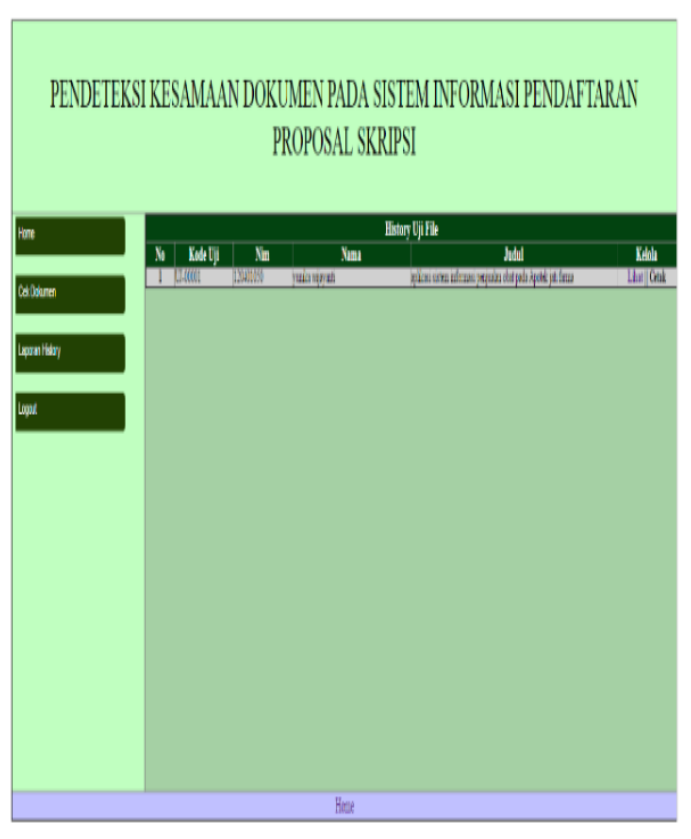

Gambar. 8 Menu Laporan History Mahasiswa 
Tampilan Menu Beranda Admin

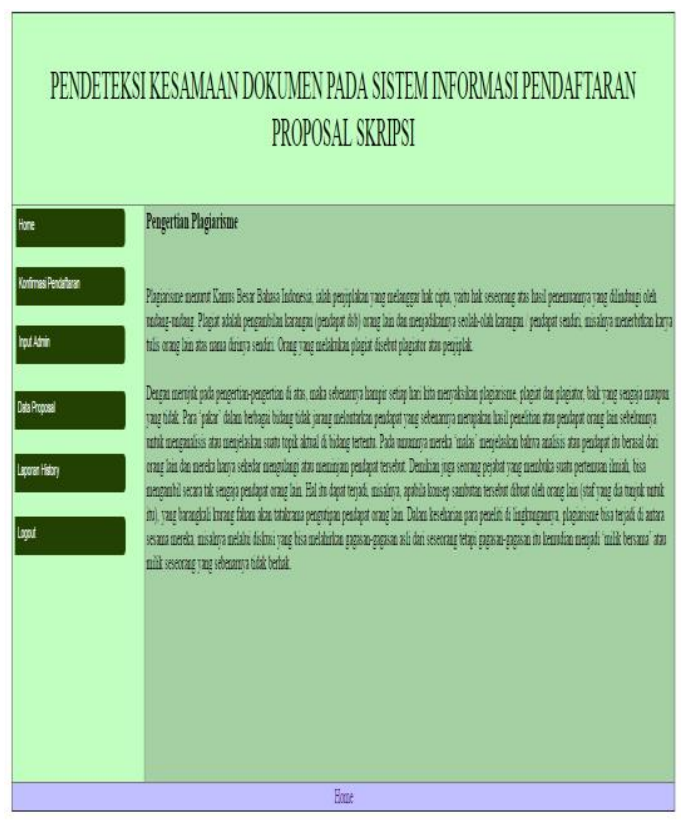

Gambar. 9 Menu Beranda Admin

\section{SIMPULAN}

1. Sistem pendeteksi kesamaan dokumen pendaftaran proposal skripsi ini dapat membantu mencegah terjadinya aksi plagiarisme pada bidang akademik. Karena mampu membandingkan satu dokumen dengan dokumen lain berdasarkan tingkat kesamaan isi dokumen yang telah ada.

2. Sistem pendeteksi kesamaan dokumen pendaftaran proposal skripsi ini mampu mengahasilkan berapa persen kesamaan dari suatu dokumen proposal skripsi.

3. Mampu mendeteksi kesamaan dokumen dengan menerapkan algoritma Rabin-Karp dalam pembuatan sistem pendeteksi kesamaan dokumen ini. 


\section{DAFTAR PUSTAKA}

Agustina, R. (2015). Sentra Penelitian Engineering dan Edukasi. Journal Speed, 7 (3), 7-12

Andi, A. (2011). Andi dan Madcoms, 2011, Aplikasi Web Database dengan Dreamweaver dan PHPMYSQL. Yogyakarta: Andi

Utorodewo, F. (2007). Sebuah Pengantar Penulisan Ilmiah Penerbit Fakultas Ekonomi Universitas Indonesia ed

KBBI. (1997). Kamus Besar Bahasa Indonesia (KBBI)

Kurniawati, A., Sekarwati, A. K. \& Wicaksana, I. W. S. (2012). Arsitektur untuk Aplikasi Deteksi Kesamaan Dokumen. Konferensi Nasional Sistem Informasi, 297302

Muslih, M. T., \& Purnama, B. E. (2013). Pengembangan Aplikasi SMS Gateway untuk Informasi Pendaftaran Peserta Didik Baru di Sman 1 Jepara. Indonesian Jurnal on Networking and Security (IJNS), 50-55

PMPN RI. (2010). Peraturan Menteri Pendidikan Nasional RI No.17, Pencegahan dan Penanggulangan Plagiat di Perguruan Tinggi, Bab 1 pasal 1 ayat 1 .

Rafles, A. (2013). Plagiarisme Dokumen dengan Pendekatan KGram Berbasis Frasa K-Gram Berbasis Frasa

Salmuasih, S., \& Sunyoto, A. (2013). Implementasi Algoritma Rabin Karp untuk Pendeteksian Plagiat Dokumen Teks Menggunakan Konsep Similarity. Seminar Nasional Aplikasi Teknologi Informatika, 23-28 